\title{
Kamu Diplomasisi Bağlamında S-400 Anlaşması'nın Uluslararası Yayın Kuruluşları Üzerinden İncelenmesi: VOA, RT VE TRT World Örnekleri
}

\author{
Şeyma Filiz (Arş. Gör.) \\ îstanbul Esenyurt Üniversitesi Sanat ve Sosyal Bilimler Fakültesi \\ seymafiliz@esenyurt.edu.tr
}

Başvuru Tarihi: 09.03.2021

Yayına Kabul Tarihi: 24.06.2021

Yayınlanma Tarihi: 30.07.2021

https://doi.org/10.17680/erciyesiletisim.890144

\section{Öz}

Karşılıklı diyalog ve ilişki inşa etmek için yeni bir iletişim ortamı sunan günümüz teknolojisi devletlerin kitlelere yönelik ilişkilerinde önemli bir rol oynamaktadır. Geniş kitlelere ulaşmanın bir aracı olarak uluslararası yayıncılık, kamu diplomasisinin önemli boyutlarından biri olarak görülmektedir. Bu çalışmanın amacı; devletler tarafından finanse edilen uluslararası haber kuruluşlarının dijital mecralarında yer alan haber içeriklerinin kamu diplomasisi bağlamında incelenmesidir. Buradan hareketle Türkiye ve Rusya arasındaki S-400 Hava Savunma Sistemleri Anlaşmasına dair haberler, uluslararası yayıncllık yapan TRT World, Russian Today ve Voice of America internet haber sitelerinde yer alan içerikler üzerinden analiz yöntemi ile incelenmektedir. Sonuçta, S-400 anlaşmasına özelinde Türkiye'ye yönelik eleștirilerin uluslararası yayın kuruluşlarında daha fazla yer aldığ görülmektedir. Bu noktada anlaşmaya taraf olan Türkiye'nin bakış açısının uluslararası alanda yansıtılması, mevcut ön yargıların ve endişelerin ortadan kaldırılması ve yabancı kamuoylarının ikna edilmesi için TRT World'ün varlığı önemlidir. Bununla birlikte gündemin sürekli olarak değiștiği uluslararası ilişkiler ortamında uluslararası yayınlar aracılığıyla 'günlük iletişim ve bilgilendirme' yapılırken kamu diplomasinin diğer boyutlarının da sürece dahil edilmesi ile uzun vadeli, kalıcı ve diyaloğa dayalı ilişkiler inşa edilmesi gerektiği sonucuna varılmıştır.

Anahtar Kelimeler: İletişim, Kamu Diplomasisi, S-400 Anlaşması, Uluslararası Yayıncılık, TRT World, Voice of America, Russian Today. 


\title{
Examining the S-400 Missile Deal in the Context of the Public Diplomacy Through International Broadcasting Organizations: The Cases of VOA, RT, and TRT World
}

\author{
Şeyma Filiz (Res. Asst.) \\ istanbul Esenyurt University Faculty of Art and Social Sciences \\ seymafiliz@esenyurt.edu.tr
}

Date Received: 09.03.2021

Date Accepted: 24.06.2021

Date Published: 30.07.2021

https://doi.org/10.17680/erciyesiletisim.890144

\begin{abstract}
New media technologies play a prominent role in building mutual dialogue and longterm relations in public diplomacy activities. As one of the essential dimensions of public diplomacy a means of reaching the target audience is international broadcasting. The aim of this study is to examine the news content of international news organizations financed by the states in the digital media in the context of public diplomacy. From this point of view, the news contents of the S-400 Air Defense Systems Deal between Turkey and Russia are analyzed through the contents of TRT World, Russian Today and Voice of America internet news sites. As a result, it is seen that the criticisms and news of sanctions against Turkey, especially the S-400 agreement, take place more in international broadcasting organizations. At this point, the role of TRT World in public diplomacy activities is crucial to reflecting the perspective of Turkey and eliminating the existing prejudices, concerns and persuading foreign public opinion in the international arena. It has been concluded that international broadcasting is effective in establishing long-term, permanent and dialog-based relations in the international relations environment where the agenda is constantly changing. While making "daily communication and information" through international broadcasting, it should be built by including the processes of other dimensions of public diplomacy.
\end{abstract}

Keywords: Communication, Public Diplomacy, S-400 Agreement, International Broadcasting, TRT World, Voice of America, Russian Today. 


\section{Giriş}

Tarihte bilinen ilk diplomasi anlaşması olan Kadeş Antlaşması'nın maddeleri Hititler ve Mısırlılar arasında kalıcı barışı sağlama ve savaşı sona erdirmeyi öngörüyordu. İlk diplomasi anlaşmasından bugüne devletlerin barış ve güvenlik ortamını tesis etme önceliklerinin devam ettiği görülmektedir. İnsanın bilgi birikiminin artması, çağlar açıp kapatarak nihayetinde günümüzdeki sınırlarına ulaşması uzun bir süreç olarak değerlendirilmektedir. 15. yüzyıldan itibaren Rönesans ile varlığından söz edebileceğimiz geleneksel diplomasi Birinci Dünya Savașı'na kadar tek yönlü ve kısa süreli olarak devletler tarafından görevlendirilmiş yetkililer aracılığıyla sürdürülmüştür. Ancak 20. yüzyılın iletişim alanındaki gelişmeleri diplomasi uygulamalarında paradigma değişikliğini getirmiş ve diplomasi uygulamaları devlet görevlilerinin tuttuğu resmi notların ötesine geçerek kitle iletişim araçlarının dahil olduğu yeni bir karar alma sürecini meydana getirmiştir (Ammon, 2001, s. 6). Yeni iletişim çağı ve teknolojik gelişmelerle birlikte ise; geleneksel diplomasiden etkileşimli bir ortama geçiş süreci yaşanmış, devletler arası dar bir alanda sürdürülen diplomasi faaliyetleri daha sonra devletler ve toplumlar arası, son olarak dijitalleşme ile birlikte toplumlar arası bir etkileşim alanı olarak ortaya çıkmıştır (Potter, 2002, s. 47). Özellikle Soğuk Savaş döneminin yarattığı iki kutuplu dünyanın tarafları olan Amerika Birleșik Devletleri ve Sovyetler Birliği, kendi ideolojilerini yayabilmek amaciyla dünya ile iletişim kurmaya önem vererek yumuşak güç unsurlarına yatırım yapmıştır. Yumuşak güç uygulamalarının Sovyetler Birliği dağılmadan önceki diplomatik pratiklerde tanınması, çağdaş tartışmalara konu olan yumuşak güç ve kamu diplomasisi kavramlarının başlangıcı olmuştur. Zaman içinde özellikle Soğuk Savaş'ın sona ermesi ile birlikte küreselleşme süreci etkinliğini arttırmış ve yumuşak güç yaklaşımı da daha anlamlı ve bilimsel açıdan açıklayıcı bir güce sahip olmuştur. Geleneksel diplomasinin yanı sıra ortaya çıkan kamu diplomasisinin önem kazanmasının temelinde otoriter devletlerin yerini demokratik yönetimlere bırakması ve yaşanan teknolojik gelişmeler ile birlikte bilginin en büyük güç haline gelmesi (Erzen, 2012, s. 53) söz konusudur.

Teknolojik gelişmelerle birlikte küreselleşmenin hız kazanması ve tek kutuplu yeni dünyanın zaman ve mekân kısıtlaması olmaksızın sunduğu iletişim ortamı, uluslararası ilişkiler ortamını da şekillendirmektedir. Bugün kamu diplomasisi ve küreselleşme kavramlarının iletişim faaliyetleri ve diğer çalıșma alanları bakımından benzerlikler taşıdığı görülmektedir. Temel olarak kamu diplomasisi, devletlerin ve toplumun çıkarları konusunda kendini küresel kamuoyuna anlatması olarak kabul edilmektedir. Küreselleşmenin etkileri dikkate alındığında kamu diplomasisi kavramının da daha önemli hale geldiği görülmektedir (Szondi, 2008, s. 6). Büyük çapta kitlelere ulaşmanın ve onlarla etkileşim kurmanın bir aracı olarak medya ise kamu diplomasisinin önemli ögelerinden biridir. Kamu diplomasisi süreçlerinde medya, hükümetlerin özellikle diş politikada hedeflenen yabancı kamuoylarına ulaşmasında, devletlerin politikalarını aktarmak ve kültürel tanıtımlarını gerçekleştirmek gibi çeşitli amaçları doğrultusunda kullanılmaktadır (Aydemir, 2016, s. 166). Bu noktada kamu diplomasisi faaliyetlerinde uluslararası yayıncılık kuruluşlarının da rolünden söz etmek mümkündür. Cull, kamu diplomasisi faaliyetlerinin dünya toplumuna iletilmesi amaçlanan haberlerin anında iletilmesinde, uluslararası yayın kuruluşlarının rolüne değinmektedir (Cull, 2008, s. 34). Devletlerin kamu diplomasisi faaliyetlerinin bir parçası olarak değerlendirilen uluslararası yayın kuruluşları, devletlerin kendilerini dış kamuoyuna ifade edebileceği bir ortam sunarak tezlerini doğru aktarabilmeleri için bir firsat tanımaktadır. Böylece dünya kamuoyunda meşru bir zemin arayışı olarak uluslararası yayıncılık kuruluşlarının 
araçsallaştırıldığı görülmektedir. Uluslararası yayıncılık kuruluşlarının kamu diplomasisi faaliyetlerinin başarısındaki rolünden hareketle bu çalışmada ilk olarak yumuşak gücün kilit bir aracı olan kamu diplomasisine değinilerek kamu diplomasi türlerinin ortak bir noktası olan uluslararası yayıncılık faaliyetlerinin kavramsal çerçevesine yer verilmektedir.

Araştırma devletler tarafından desteklenen uluslararası yayın kuruluşlarının kamu diplomasisi faaliyetlerinin bir parçası olarak nasıl rol aldığı sorunsalından hareketle, Türkiye ve Rusya arasındaki S-400 Hava Savunma Sistemleri Anlaşmasını uluslararası yayıncılık kuruluşlarının kamu diplomasisi faaliyetleri bağlamında ele almaktadır. Türkiye ile Rusya arasında 2,5 milyar dolar değerindeki 4 taburlu sofistike Rus hava savunma sisteminin satışı ile ilgili imzalanan S- 400 anlaşmasının, uluslararası arenada ve özellikle NATO müttefikleri tarafından Türkiye'ye yönelik eleştirilere yol açtığı bilinmektedir (Kibaroğlu, 2019, s. 3). Özellikle Türkiye'nin Rusya yapımı S-400'ler ile ilgilendiğini duyurmasından itibaren ABD'nin F-35 ittifakının savunma sistemlerinin baltalanacağı iddiasıyla, Türkiye'nin S-400 alımına karşı çıkması, F-35 avcı uçağının Türkiye'ye teslimini askıya alması ve halka açık bir şekilde Türkiye'nin projeye katılımını gevşetmeyi taahhüt etmesi S-400 Anlaşmasına taraf olan Türkiye ve Rusya dışında Amerika Birleşik Devletleri'ni de taraf haline getirmiştir (Keşvelioğlu ve diğerleri., 2019). Buradan yola çıkarak anlaşmaya taraf olan Türkiye'nin TRT World ve Rusya'nın Russian Today yayın kuruluşları ile birlikte Amerika Birleşik Devletleri'nin Voice of America yayın kuruluşu aracılığıyla S-400 Anlaşmasına yönelik haberlerinin kamu diplomasisi bağlamında incelenmesi çalışmanın önemi olarak görülmektedir.

Çalışmada Joseph Nye'ın kamu diplomasisinin boyutları sınıflandırması üzerinden TRT World, Russian Today ve Voice of America'nın web sitelerinde yer alan S-400 Hava Savunma Sistemleri Anlaşmasına dair haber içerikleri incelenmektedir. Örneklem olarak alınan uluslararası yayın kuruluşlarının S-400 Anlaşmasına dair haber içerikleri anlaşmanın ilk kez gündeme geldiği Eylül 2017 yılından itibaren 2019 yılı Ekim ayını kapsayan süreçte ele alınarak içerik analiz yöntemi ile analiz edilmektedir.

\section{Kamu Diplomasisine Kavramsal Bir Bakış}

"Kamu diplomasisi" terimi, ilk kez 1964 yılında eski ABD Büyükelçisi Edmund Gullion tarafından modern anlamıyla diplomatik ilişkilerin yürütülmesi amacıyla kamuoylarını tesir altına alabilecek bir etki şekli olarak tanımlanmıştır. Gullion'a göre kamu diplomasisi, kamuoyunda tutum oluşturma ve dış politikanın yürütülmesi gibi amaçlarla ilgilenmekte ve iletişimciler diplomatlar ve dış temsilciler arasındaki kültürlerarası iletişimi kapsamaktadır (Pamment, 2012, s. 6). Günümüzde, kamu diplomasisinin bir toplumdan diğer toplumlara yönelik faaliyetleri içermesi, kamu diplomasisinin uzun vadeli ilişki inşa etme amaçlarına hizmet etmektedir. Hans N. Tuch ise, "Dünya ile iletişim: ABD Kamu Diplomasisi" kitabında kamu diplomasisini, "hükümetin uluslarının fikirleri ve idealleri, kurumları ve kültürleri, ayrıca ulusal hedefleri ve mevcut politikaları hakkında bir anlayış kazanma çabası içinde yabancı halklarla iletişim kurma süreci" olarak tanımlamaktadır (Tuch, 1990, s. 3). Kamu diplomasisinde devlet politikalarının dışında ulusun fikir ve ideallerinin de yabancı halklarca tanınmasının sağlanması, onun kültürlerarası diyaloğu gerçekleştirebilecek potansiyele sahip olduğunu ifade etmektedir (Sancar, 2015, s. 3). Snow ise geleneksel kamu diplomasisini, devletlerin uluslararası kamularla iletişimi ve ulusal çıkarlarını korumak amacıyla dış politikada destek sağlayabilmek amacıyla bilgilendirme, etkileme ve ilgi çekmeye yönelik çabaları olarak tanımlamaktadır (Snow \& Taylor, 2008, s. 6). Bu tanımdan hareketle kamu diplomasisi faaliyetlerinin, ülkelerin dış politikalarına 
destek sağlaması amacıyla dış hedef kitlelere ulaştırılabilmesi için uluslararası yayıncılık ve dijital medya araçları önemli bir yere sahiptir. Tanımlardan hareketle, uluslararası kamuoyunu etkilemenin ve uluslararası ilişkilerin aktörleri olan devletler ve halklarına yönelik iletişimin, kamu diplomasisi yöntemleri kullanılarak gerçekleşmesi mümkün görünmektedir. Diğer bir ifadeyle kamu diplomasisi, ülkelerin özlerinde var olan değer, fikir ve ideallerinin dış hedef kitlelerle karşılıklı anlayışı geliştirme ve ilişki inşa etmek üzere planlanan iletişim çabaları olarak ele alınabilmektedir.

\section{Yumuşak Gücün Uygulama Aracı olarak Kamu Diplomasisi}

Joseph Nye; uluslararası ilişkilerde askeri ve ekonomik güç yerine sert güce doğrudan dayalı olmayan kültür, politik değerler ve dış politika kaynaklarının kullanılmasını yumuşak güç olarak tanımlanmaktadır (Nye, 2005, s. 5). Nye'ın tanımından hareketle etkileme, ikna ve çekicilik çabalarının bir parçası olarak yumuşak güç, sert güçten ayrılarak konjonktüre bağlı uluslararası ilişkiler uygulamalarına yön veren yeni bir yaklaşım olarak ele alınmaktadır. Diğer yandan, Joseph Nye tarafından kavramsallaştırılan yumuşak gücün en kilit uygulama aracı kamu diplomasisi, yumuşak iktidarın cephaneliğinde önemli bir araç olarak görülmekte ve belli bir anlamda yumuşak güce ulaşabilmenin bir yöntemi olarak kullanılmaktadır (Nye, 2008, s. 95). Yumuşak gücün kamu diplomasisi aracılı̆̆ıyla uygulanması ise, çeşitlenen iletişim araçları ile ilişkilendirilmektedir. Devletler, uluslararası ilişkilerde sert güç kullanmak yerine iletişim araçları vasıtasıyla yabancı kamuoylarını etkilemeyi iknaya dayalı olarak daha cazip bulmaktadırlar. Siyasi, ekonomik ve kültürel bağlamda farklılıkları olan ülkeler için kamuoyunu etkilemenin yollarından biri de uluslararası yayın kuruluşları aracılığıyla karşılıklı anlayışın inşa edilmesidir. Devletlerin olumlu medya mesajları ile hedef kitleleri etkileme çabası kamu diplomasisi faaliyetlerinin başarısını etkilemektedir. Yumuşak gücün uygulama alanı olarak kamu diplomasisi, dış kamuoylarını etkilemek ve karşılıklı inşa etmek üzere planlı iletişim çabalarını içermektedir. Buradan hareketle kamu diplomasisinin farklı amaçlar doğrultusunda tasarlanabileceği gibi farklı boyutları ile de ele alındığı görülmektedir. Joseph Nye, kamu diplomasisini farklı boyutlarıyla ele alarak; kısa ve uzun vadeli kamu diplomasisi uygulamalarına çerçeve sunmaktadır.

Tablo 1. Joseph Nye'ın Kamu Diplomasisi Boyutları

\begin{tabular}{|l|l|}
\hline Birinci Boyut & Günlük İletişim ve Bilgilendirme \\
\hline İkinci Boyut & Stratejik Planlama ve Ülke Markalaşması \\
\hline Üçüncü Boyut & Uzun Vadeli İlişkilerin Kurulması ve Kurumsallaşması \\
\hline
\end{tabular}

Kamu diplomasisinde birinci boyut, yerel ve dıș politikaların hedef kitlelere aktarılması için "günlük iletişim ve bilgilendirme", ikinci boyut, uzun vadeli planların yapıldığ "stratejik planlama ve ülke markalaşması" ve üçüncü boyutu ise, karşılıklı diyalog ve ilişki ortamını inşa etmeyi öngören "uzun vadeli ilişkilerin kurulması ve kurumsallaşması" olarak ele alınmaktadır (Nye, 2005, s. 108-109). Özellikle uluslararası yayıncılık kuruluşları aracılığıyla gerçekleştirilen günlük iletişim, kamu diplomasisinin boyutları içinde günlük iletişim ve bilgilendirme olarak ele alınmaktadır. Devletlerin, dış hedef kitlelere yönelik açıklamalar ve bilgilendirmeler hazırlayarak kamuoyunda gündeme geldiği haberler, günlük iletişim akışı içerisinde önemli bir yere sahiptir. Sadece dış politikayı destekleyici açıklamalar değil aynı zamanda dış kamuoyunda gündeme gelen eleștiri haberlerine de hızlıca/ eş zamanlı cevap verebilmek için günlük iletişim önemlidir. Nye günlük bilgilendirme boyutu ile ortaya çıkan krizler ve saldırılarla mücadele edilebileceğini ifade etmektedir. Böylece, günlük iletişim ve bilgilendirme ile olası krizlere hazırlıklı olarak ve anlık karşılık verebilme kabiliyeti ve haksız suçlamaların 
ve yanlış bilgilerin ivedilikle cevaplandırılabilmesi mümkün olmaktadır (Nye, 2005, s. 154). Kamu diplomasi uygulamalarının toplumlar arasında uzun süreli, kalıcı ilişkilere ulaşabilmesi beklenirken diğer boyutların aksine günlük boyut, geçici olarak ortaya çıkan konular özelinde, seçilen hedef kitlelere ulaşabilmeyi amaçlamaktadır. Bu noktada, önceden belirlenen hedef kitlelere yönelik sürekli haber akışını sağlanması, özellikle dış basında yayınlanabilecek olan açıklamaların stratejik olarak seçilmesi önem arz etmektedir. Bu noktada iç kamuoyuna yönelik açıklamalarda dikkatli hareket etmek, açıklamaların dişarıda nasıl algılanabileceğini tahmin etmek, konuya yönelik ilgiyi canlı tutmak için gündemde kalmak ve haberleri bütünsel bir yaklaşımla ele almak (Nye, 2005, s. 108) önemli bir yere sahiptir.

\section{Uluslararası Yayıncılık ve Kamu Diplomasisi Ilişkisi}

Küreselleşen dünyada devletlerin uluslararası ilişkilerin başat aktörü olduğuna dair paradigmanın özellikle Berlin Duvarı'nın yıkılışı ve ABD’deki 11 Eylül saldırıları ile dönüşüme uğradığı görülmektedir. Değişen paradigma ile devletin yanında yeni aktörler eklenmiş; devlet dişı aktörler, sivil toplum kuruluşları, uluslararası örgütler, çok uluslu şirketler gibi aktörler etkinliğini göstermeye başlamıştır (Keyman, 2000, s. 17). Bu dönemde, devlet dışı bir aktör olarak medyanın giderek etkin bir güç haline gelmesi, ulus ötesi sınırlara ulaşabilen uluslararası yayıncılık faaliyetlerini de şekillendirerek ulusların kendilerini yabancı kamuoylarına anlatabilmesi önemli hale gelmiştir. Küreselleșme ile birlikte yeni iletişim teknolojilerinin de sürece dahil edilmesiyle devletler doğrudan küresel kamuoyuna ulaşabilme imkanına sahiptir. Bu noktada karşılıklı anlayış ortamının inşa edilebilmesi için kamu diplomasisi faaliyetlerinin öneminin giderek arttığ görülmektedir (Bostancl, 2012, s. 44).

McLuhan'ın ifadesiyle küreselleşme ve iletişim bağlamında dünyamızı küresel bir köy haline getiren dönüşüm süreci; ekonomi, eğitim, siyaset, iletişim gibi birçok alanda değişimi meydana getirmektedir. Hızlı gerçekleșen bu dönüşüm sürecinde devletler çıkarlarını korumak için kamu diplomasisi faaliyetlerine odaklanmaktadır (Yağmurlu, 2007, s. 33). Cull'un ifadesiyle kamu diplomasisi, diplomatik iletişimden daha fazla araca sahip olarak devletlerden yabancı toplumlara ve toplumlar arasında bir bilgi akışı sunmaktadır (Cull, 2006). Bu noktada, kamu diplomasisinde uluslararası iletişimin bir aracı olarak uluslararası yayıncılık önemlidir. Batı merkezli bilgi güçtür anlayışının ithaf ettiği uluslararası toplumları ikna etme yöntemleri, uluslararası yayınlar aracılığıyla gerçekleşmektedir. Özellikle televizyon yayıncılığının ortaya çıkması ile birlikte devletler uluslararası yayıncılık alanında çalışmalar yürütmeye başlamış ve geniş hedef kitlelere mevcut politikalarını anlatabilmek ve gündem oluşturmak için yayıncılık yapan televizyon kanallarının kurulmasında gereken hassasiyeti göstermiş̧lerdir (Özkan, 2012). Bununla birlikte yeni iletişim ortamının sunduğu çok boyutlu bilgi ortamı sayesinde televizyon yayıncılığı yapan kuruluşlar bugün dijital platformlardaki yayınları aracılığıyla geniş hedef kitlelere anlık olarak ulaşabilmekte ve etkileşimli bir ortam sunabilmektedir.

İletişim teknolojileriyle gelişimiyle birlikte dijital platformlar aracılığıyla geniş çaplı hedef kitlelere ulaşmanın bir yöntemi olarak uluslararası yayıncılık, devletten topluma ya da toplumdan topluma gerçekleștirilen yeni bir diplomasinin uygulama aracı haline gelmektedir. Yeni medya araçlarının kültürlerarası iletişimi eş zamanlı hale getirdiği yeni iletişim çağında, kamu diplomasisi faaliyetleri medya aracılığıyla kalıcı hale getirilmektedir. Devletler veya sivil toplum kuruluşları gibi aktörler bilgi akışında uluslararası medyadan faydalanmakta ve kamu diplomasisi faaliyetleri için iletilmesi amaçlanan haberlerin anlık olarak gönderilmesi uluslararası yayıncılık aracılığıyla gerçekleşmektedir (Cull, 2008, s. 
34). Buradan hareketle, uluslararası yayıncılık bağlamında kamu diplomasisi, ülkelerin belirli hedefleri doğrultusunda diğer ülkelerin vatandaşlarını kamuoyu oluşturarak etkilemeyi amaçlaması olarak ifade edilebilir. Böylece devletler politikalarının dünya kamuoyunda meşru hale gelmesi için çaba gösterme (Nye, 2005, s. 5), belirli amaçlar doğrultusunda sahip oldukları yumuşak güç araçlarından faydalanmaktadırlar.

\section{VOA, RT ve TRT World’ün Yayıncilığı}

Bu çalışmaya konu olan Türkiye ve Rusya arasındaki S-400 Anlaşmasının uluslararası yayın kuruluşlarında incelenmesi amacıyla Anlaşmaya taraf olan Rusya'nın Russian Today, Türkiye'nin TRT World ve ayrıca Amerika Birleşik Devletleri'nin Voice of America uluslararası yayın kuruluşlarının söz konusu anlaşmaya yönelik haberleri ele alınmaktadır. Seçilen haber kuruluşlarının devletlerce finanse edilerek uluslararası yayınlar yapması ve ülkelerin kamu diplomasisi faaliyetlerinin bir unsuru olarak kullanılması çalışmada devletlerin yabancı kamuoyların etkilemek üzere gerçekleştirdikleri kamu diplomasisi çalışmalarını anlamak adına önemli bir yere sahiptir.

Amerika'nın Sesi (VOA)'nın web sitesinde yer alan bilgilere göre ("Voice of America", 2021); 1942 yılında yayınlarına başlayan VOA, haftalık olarak 280 milyondan fazla haftalık izleyiciye sahip 40'tan fazla dilde haber ve bilgi sağlayan en büyük uluslararası yayıncılardan biridir. Dijital, televizyon ve radyo platformları için içerik üreten VOA, askeri olmayan tüm ABD yayınlarını denetleyen devlet kurumu olan ABD Küresel Medya Ajansı'nın (USAGM) bir parçasıdır ve ABD Kongreleri tarafından finanse edilmektedir. Web sitesinde yer alan bilgilere göre VOA'nın misyonu; Amerika Birleşik Devletleri'nin uzun vadeli çıkarlarına, doğrudan dünya halklarıyla radyo yoluyla iletişim kurarak hizmet verilmesidir. VOA yayınlarını şekillendiren ilkeler; Amerikan düşünce ve kurumlarının bir projeksiyonunu sunmak, Amerika Birleşik Devletleri politikalarını açık ve etkili bir şekilde sunacak ve politikaları hakkında sorumlu tartışmalar ve görüșler sunmak olarak ifade edilmektedir. Bu bilgilerden hareketle, VOA'nın yayınlarının ABD'nin temsil ettiğini ve kurumsal açıklamalarının dünyaya yansıtılmış bir projeksiyonu olma görevini üstlendiği söylenebilir.

Russia Today haber ajansı web sitesinde yer alan bilgilere göre kuruluş ("Russian Today", 2021), 2005 yılında piyasaya sürülen ilk uluslararası haber kanalıyla, altı dilde yayın yapan dijital platformlar ve RUPTLY video haber ajansı olan sekiz TV kanalı, yayın haberleri, güncel olaylar ve belgesellerden oluşan küresel, gündelik bir haber ağıdır. İngilizce, Arapça, İspanyolca ve belgesel yayın yapan RT, günümüzde, 100'den fazla ülkede yayın faaliyetlerini yürütmektedir. RT, Rusya Federasyonu bütçesinden finanse edilen özerk, kâr amacı gütmeyen bir organizasyondur. RT'nin web sitesinde yer alan bilgilerden hareketle RT, devlet tarafından finanse edilerek ana akım medya tarafından gözden kaçırılan hikayeleri paylaşmayı ve uluslararası izleyicileri büyük küresel olaylar hakkındaki Rus bakış açısıyla tanıştırmayı amaçlayan bir kuruluştur. Ana akım medyanın yanı sıra sosyal medyada platformlarında da varlığını gösteren RT'nin Rusya perspektifinden haberler paylaşmayı amaçlaması, Rusya'nın kamu diplomasisi faaliyetlerinin bir aracı olarak değerlendirilebilir.

2015 yılının Kasım ayından itibaren yayına geçen TRT World'ün amacı, insana dair olan her şeyi Türkiye'nin ve bulunduğumuz coğrafyanın gözüyle ele alıp yayınlamak olarak ifade edilmektedir (Devran, 2016, s. 290). TRT Word'ün web sitesinde yer alan bilgilere göre ("TRT World", 2021); misyonu anlayıșı genişletmek, varsayımlara meydan okumak, tartışmayı teşvik etmek ve olumlu davranışları etkilemek olarak açıklanırken vizyonu ise, 
pozitif değişim için bir katalizör olmak olarak belirtilmiştir. Buradan hareketle, Televizyon yayıncılığı dışında gelişen yeni iletişim ortamının getirdiği zorunlu bir yumuşak güç ihtiyacı olarak TRT World'ün sosyal medya platformlarındaki varlığı; Türkiye'nin dış kamuoyunda olumlu temsili ve kamuoyları ile etkileşimi bakımından önemlidir. Ayrıca TRT World'ün, dünyada gerçekleşen olayları Türkiye'nin bakış açısıyla değerlendirip dünya gündemini bu doğrultuda oluşturmayı amaçlaması, özellikle Türkiye'yi ilgilendiren her türlü konuda başvurulan ilk kaynak olması için yaptığı yayınlar, Türk kamu diplomasisini geliştirmeye yönelik yatırımlar olarak değerlendirilebilir (Baritci \& Aydeniz, 2019, s. 1571).

\section{Araştırma Verilerinin Analizi ve Bulgular}

Çalışmada, S-400 Anlaşmasının resmi makamlar tarafından ilk kez gündeme geldiği Eylül 2017 yılından itibaren anlaşmanın tamamlandığı 2019 yılı Ekim ayını kapsayan süre içerisinde, seçilen uluslararası yayın kuruluşlarının S-400 Anlaşmasına yönelik haberleri kapsayan konu başlıkları belirlenerek içerik analiz yöntemi ile analiz edilmektedir. Araştırmada seçilen Voice of America, Russian Today ve TRT World'ün Türkiye ve Rusya arasındaki S-400 Anlașmasına dair İngilizce haberleri incelendiğinde haberleri kapsayan konular belirlenmiştir. Buna göre ilk olarak; S-400 Anlaşmasının gündeme geldiği, Türkiye ve Rusya arasında görüşmelerin yapıldığı ve anlaşmanın imzalandığı sürece dair haberler, ikinci olarak; S-400 Hava Savunma Sistemlerinin teknik özelliklerinin ve teslimat sürecinin gündeme geldiği haberler ele alınmaktadır. Üçüncü olarak; S-400 Anlaşmasına yönelik NATO/AB ülkelerinin açıklamaları, F-35 programında Türkiye'nin görevinin askıya alınması ve Amerika Birleşik Devletleri'nin Türkiye'ye yönelik yaptırım açıklamalarına dair haberler ele alınmaktadır. Dördüncü olarak ise; Türkiye'nin neden hava savunma füzesine ihtiyaç duyduğu ve S-400 Hava Savunma Sistemleri ile ilgilendiğini açıkladığı ayrıca NATO ülkeleri ve ABD’nin endişelerine yönelik cevap verdiği haberler ele alınmaktadır.

Tablo 2. S-400 Anlaşmasına İlişkin Ön Plana Çıkan Haber Konuları

\begin{tabular}{|l|l|c|c|c|c|c|}
\hline Ülke & $\begin{array}{l}\text { Yayın } \\
\text { Kuruluşu }\end{array}$ & $\begin{array}{c}\text { S-400 } \\
\text { Anlaşması }\end{array}$ & $\begin{array}{c}\text { S400'lerin } \\
\text { ozzllikleri ve } \\
\text { teslimat süreci }\end{array}$ & $\begin{array}{c}\text { NATO ve ABD'nin } \\
\text { açıklamaları }\end{array}$ & $\begin{array}{c}\text { Türkiye'nin } \\
\text { açıklamaları }\end{array}$ & Toplam \\
\hline Türkiye & TRT World & 17 & 11 & 33 & 33 & 94 \\
\hline Rusya & RT & 34 & 10 & 43 & 34 & 121 \\
\hline ABD & VOA & 20 & 10 & 43 & 18 & 91 \\
\hline Toplam & & 71 & 31 & 119 & 85 & 306 \\
\hline
\end{tabular}

Tabloda yer alan haber konuları genel olarak değerlendirildiğinde; VOA, RT ve TRT World'ün web sitelerinde 2017 yılı Eylül ayı ve 2019 yılı Ekim ayını kapsayan süre içerisinde anlaşmaya yönelik 306 haberin yayınlandığı tespit edilmiștir. Yayınlanan haberlerden 71'inin S-400 Anlaşmasının detaylarına ilişsin iken 31'inin S-400'lerin özelliklerine ve teslimat sürecine yöneliktir. ABD başta olmak üzere diğer NATO ülkelerinin anlaşmaya yönelik eleştirilerini, ABD’nin Türkiye'ye yönelik yaptırım tehditlerini ve Türkiye'nin F-35 programındaki rolünü askıya alan toplamda 119 haber ve Türkiye'nin açıklamalarını içeren 85 haber içeriğinin yayınlandığı tespit edilmiştir. Buradan hareketle anlaşmanın politik yönünün ön plana çıkarak S-400'lere dair teknik bilgilerin dış kamuoyunda daha az gündeme geldiği görülmektedir. 


\section{S-400 Anlaşmasına Dair Voice of America İnternet Haber Sitesinde Yer Alan Haberlerin İçerik Analizi}

İlk olarak Voice of America'nın web sitesi incelendiğinde, Türkiye ile Rusya arasındaki S-400 Anlaşmasına dair yayınlanan 91 haber olduğu görülmektedir. Anlaşmaya dair ilk haberin 9 Mart 2017 tarihinde verilmesi ve sonrasinda 26 Temmuz 2017 tarihinde anlaşmaya yönelik haberlerin gündeme geldiği görülmektedir. 2017-2019 yılları arasında S-400 anlaşmasının detaylarına ilişkin 20 haber yayınlanırken, S-400'lerin özelliklerine, teslimat sürecine ve aktivasyonuna yönelik 10 haber yer almaktadır. Örneğin VOA'nın haber içerikleri incelendiğinde, 29 Aralık 2017 tarihinde yayınlanan "Türkiye, S-400 Füzelerinin Tedariği için Rusya ile Anlaşma İmzaladı" başlıklı haberde teslimata dair bilgiler yer almaktadır. Benzer tarihlerde RT ve TRT World'ün web sitesinde teslimata dair bilgi vermez iken VOA'nın teslimat için tarih belirtmesi S-400'lerin teslimatına yönelik dikkat çekmektedir. Bununla birlikte Voice of America'nın web sitesinde S-400 Anlaşmasına dair en çok yayınlanan haberlerin ABD'nin ya da diğer NATO ülkelerinin anlaşmaya yönelik eleştirileri ve Türkiye'ye yönelik yaptırımları olarak görülmektedir. Özellikle yaptırımların ve F-35 programında Türkiye'nin görevinin askıya alınması haberleri ön plana çıkmaktadır. Örneğin VOA'nın web sitesinde "ABD Yetkilisi Türkiye'yi Rusya Sistemi Üzerinden F-35 Anlaşması konusunda Uyardı" başlığıyla yayınlanan 26 Haziran 2018 tarihli haberde, ABD yetkililerinin açıklamalarına yer vererek Türkiye'nin S-400 Sistemini satın alması durumunda F-35 uçakları ile uyumunun sağlanmayacağına dikkat çekilmektedir. Türkiye'yi anlaşmadan vazgeçirmeye yönelik yayınlanan açıklamaya dayalı haberlerin devamında Türkiye'nin açıklamaları ile birlikte yaptırım haberlerinin gündeme geldiği görülmektedir.

Genel olarak VOA'nın web sitesinde yer alan konu başlıkları incelendiğinde ABD ve diğer NATO ülkelerinin açıklamalarına dair 43 haber yayınlanırken Türkiye'nin anlaşmaya yönelik resmî açıklamalarından 18'inin yer aldığı görülmektedir. 12 Temmuz 2019 tarihinde S-400 Hava Savunma Sistemlerinin Türkiye'ye ilk tesliminin yapılması ile ilgili olarak ise 12 Temmuz 2019 tarihinde yayınlanan "Rus S-400 Savunma Sisteminin İlk Parçaları Türkiye'ye Geldi” başlıklı haberlerin devamında, 16 Temmuz 2019 tarihli 'Savunma Sekreteri Adayı, Türkiye'nin S-400 Anlaşmasını 'Yanlış' ve 'Hayal Kırıklığı' İfadesiyle Eleştirdi" başlıklı haberde, Türkiye'ye teslimatı yapılan S-400 Hava Savunma sistemlerine yönelik eleștiriler yer almaktadır. Türkiye'nin resmî açıklamalarına dair haberlerin ise, ABD'nin eleștirileri ile birlikte yer alması dikkat çekmektedir. Ayrıca VOA'da Türkiye ve ABD ilişkilerine yönelik yayınlanan 6 Ağustos 2019 tarihli raporda Türkiye'nin güvenilir bir NATO müttefiki olup olmadığının tartışıldığı ve güncel sorunların S-400 Anlaşması üzerinden ele alındı̆̆ı görülmektedir.

Tablo 3. Konularına Göre Voice of America Internet Haber Sitesinde Yayımlanan Haber Başlığı Örnekleri

\begin{tabular}{|l|l|l|}
\hline Konu & Haber Başlığı & Tarih \\
\hline S-400 Anlaşmasına dair haber & $\begin{array}{l}\text { “Türkiye, S-400 Füzelerinin Tedariği } \\
\text { için Rusya ile Anlaşma İmzaladı” }\end{array}$ & 29 Aralık 2017 \\
\hline Teslimat sürecine dair haberler & $\begin{array}{l}\text { "Rus S-400 Savunma Sisteminin } \\
\text { ilk Parçaları Türkiye'ye Geldi” }\end{array}$ & 12 Temmuz 2019 \\
\hline $\begin{array}{l}\text { NATO ve ABD' nin anlaşmaya } \\
\text { yönelik açıklamalarına dair haberler }\end{array}$ & $\begin{array}{l}\text { “ABD Yetkilisi Türkiye'yi Rusya } \\
\text { Sistemi Üzerinden F-35 Anlaşması } \\
\text { konusunda Uyardı" }\end{array}$ & 26 Haziran 2018 \\
\hline $\begin{array}{l}\text { Türkiye'nin anlaşmaya yönelik } \\
\text { açıklamalarına dair haberler }\end{array}$ & $\begin{array}{l}\text { "Savunma Sekreteri Adayı, Türkiye'nin } \\
\text { S-400 Anlaşmasını 'Yanlış' ve 'Hayal } \\
\text { Kırıklığı' İadesiyle Eleştirdi” }\end{array}$ & 16 Temmuz 2019 \\
\hline
\end{tabular}




\section{S-400 Anlaşmasına Dair Russian Today'in İnternet Haber Sitesinde Yer Alan Haberlerin İçerik Analizi}

Russian Today haber kuruluşunun web sitesinde Türkiye ve Rusya arasındaki S-400 Anlaşmasına dair yayınlanan haberler incelendiğinde toplamda 121 haberin yayınlandığı görülmektedir. RT’nin web sitesinde, S-400 Hava Savunma Sistemlerinin tedarikçisi konumundaki Rusya'nın anlaşmanın detaylarına ve ödeme ile ilgili başlıklara yönelik haberlerinin yanı sıra S-400'lerin özelliklerini ve teslimat sürecini içeren 44 haber yer almaktadır. Örneğin, anlaşmanın ertelendiğine yönelik çıkan haber sonrasında 15 Mayıs 2019 tarihinde “Türk Dışişleri Bakanı, Ankara'nın Rus S-400 anlaşmasını ertelediğini reddetti." başlığıyla yayınlanan habere göre anlaşmanın devam edeceğine yönelik Türkiye'nin açıklamalarına yer verilirken, 12 Mayıs 2019 tarihli "ABD anlaşma konusunda Ankara üzerindeki baskıyı artırırken, Rusya Türkiye'ye S-400 teslimatına başladı" başlıklı haberde ise teslimat sürecine ilişkin gelişmelere yer verilmektedir. VOA ve TRT World'ün web sitelerinde yayınlanan haberler ile kıyaslandığında RT'nin web sitesinde anlaşmanın detaylarına yönelik daha fazla haberlerin yayınlanması, Rusya'nın iç kamuoyunu söz konusu anlaşmaya yönelik bilgilendirmesi ve anlaşmaya dair güveninin sağlanmasına yönelik hedeflerle ilişkilendirilebilir. Yayınlanan haberlerde, Rusya'nın NATO ülkesi olan Türkiye'ye S-400 Savunma Füzelerini satmasının yaratabileceği endișeleri ortadan kaldırmak için hükümet yetkililerinin, halka yönelik açıklamaları ön plana çıkmaktadır. RT haber kuruluşunda, NATO ülkelerinin ve özellikle ABD’nin anlaşmaya yönelik açıklamalarını içeren 43 haber yer almaktadır. Haber içeriklerini, Türkiye'ye yönelik yaptırımlar, Türkiye'nin F-35 programındaki rolünün askıya alınması ve NATO ilişkileri, Türkiye ve ABD arasındaki anlaşmazlıklar kapsamaktadır. Türkiye'nin resmi makamlarınca yapılan açıklamaların en fazla yayınlandığı kuruluş olarak RT, Türkiye'nin anlaşmaya yönelik bakış açısının yanı sıra yaptırım tehditleri ve eleştirilere yönelik açıklamalarına yayınlanmış olan 34 haberde yer vermektedir. 22 Mayıs 2019 tarihinde yayınlanan Rusya yetkililerince yapılan açıklamaları içeren “ABD’nin S-400'ler üzerinden Türkiye'ye yönelik ültimatomlarının kabul edilemez" olduğuna yönelik haber, Rusya ve Türkiye'nin resmî açıklamalarının birbirini desteklediğine örnek olarak gösterilebilir. 24 Haziran 2019 tarihinde yayınlanan "Anlaşma yapıldı: Türkiye, Rusya yapımı S-400'leri 'zaten satın alınmış' olduğunu ve ABD yaptırımlarının bunu değişmeyeceğini söyledi” başlıklı habere göre, Türkiye'nin resmi makamlarınca yapılan açıklamalara yer verilerek ABD’nin yaptırım tehditlerine yönelik Türkiye'nin bakış açısının yansıtılması dikkat çekmektedir.

RT’nin kuruluş amacı ve misyonu düşünüldüğünde, Rusya'nın politikalarının dış hedef kitlelere aktarılması bakımından S-400 Anlaşmasına yönelik haberler önemli bir yere sahiptir. Rusya'nın anlaşmanın tarafı olarak anlaşmaya yönelik resmî açıklamalara yer vermesi ve anlaşmaya yönelik eleştirileri ele alırken Rusya bakış açısını yansıtması hem siyasi hem ekonomik hem de askeri ilişkileri bağlamında ön plana çıkmaktadır. Anlaşmaya yönelik en fazla haberin yayınlandığı Russia Today haber kuruluşunun, anlaşmanın detaylarını takip ederek yayınlar yaptığı ve web sitesinin sunduğu haber içeriklerini tartışma ortamı sunduğu görülmektedir. 
Tablo 4. Konularına Göre Russian Today İnternet Haber Sitesinde Yayımlanan Haber Başlığı Örnekleri

\begin{tabular}{|l|l|l|}
\hline Haber Konusu & Haber Başlığı & Yayın Tarihi \\
\hline S-400 Anlaşmasına dair haber & $\begin{array}{l}\text { “Türk Dışişleri Bakanı, Ankara'nın Rus } \\
\text { S-400 anlaşmasını ertelediğini reddetti.” }\end{array}$ & 15 Mayıs 2019 \\
\hline Teslimat sürecine dair haberler & $\begin{array}{l}\text { "ABD anlaşma konusunda Ankara } \\
\text { üzerindeki baskıyı artırırken, Rusya } \\
\text { Türkiye'ye S-400 teslimatına başladı” }\end{array}$ & 12 Temmuz 2019 \\
\hline $\begin{array}{l}\text { NATO ve ABD' nin anlaşmaya yönelik } \\
\text { açıklamalarına dair haberler }\end{array}$ & $\begin{array}{l}\text { "ABD'nin S-400'ler üzerinden Türkiye'ye } \\
\text { yönelik ültimatomlarının kabul edilemez" }\end{array}$ & 26 Haziran 2018 \\
\hline $\begin{array}{l}\text { Türkiye'nin anlaşmaya yönelik } \\
\text { açıklamalarına dair haberler }\end{array}$ & $\begin{array}{l}\text { "Anlaşma yapıldı: Türkiye, Rusya } \\
\text { yapımı S-400'leri 'zaten satın alınmış' } \\
\text { olduğunu ve ABD yaptırımlarının } \\
\text { bunu değişmeyeceğini söyledi” }\end{array}$ & 24 Haziran 2019 \\
\hline
\end{tabular}

\section{S-400 Anlaşmasına Dair TRT World‘ün İnternet Haber Sitesinde Yer Alan Haberlerin İçerik Analizi}

TRT World'ün web sitesinde S-400 Anlaşmasına yönelik 94 haber yayınlandığı görülmektedir. 18 Ağustos 2017 tarihinde yayınlanan "Neden Türkiye Rusya'nın S-400 Savunma Sistemini Satın Alıyor?” başlıklı haberde, Türkiye’nin S-400 alma gerekçelerini içeren ilk haber yayınlanarak Türkiye'nin savunma füzesi ihtiyacı ve sınır güvenliğine dair endişeleri ile S-400'lerin özelliklerine dair bilgilere yer verilmektedir. İlk haberden yola çlkarak TRT World'ün web sitesinde, anlaşmanın detaylarına, S-400'lerin özelliklerine ve teslimat sürecine ilişkin 28 haber yayınlandığı görülmektedir. Ödemenin yapılmaya başlandığına dair 12 Eylül 2017 tarihli ve "Türkiye S-400 Füzelerine Ödeme Yapmaya Başlıyor" başlıklı haberde, Astana görüşmeleri sonrasında Türkiye tarafından ödemelerin yapılmaya başlandığına dair devamındaki günlerde ise Rusya'nın teslimatı hızlandıracağına dair haberler yayınlandığı görülmektedir. TRT World tarafından yayınlanan 33 haberde Türkiye'nin resmi makamlarınca yapılan açıklamalara yer verilmesi, anlaşmanın tarafı olarak Türkiye'nin bakış açısının dış kamuoylarına aktarılması açısından önemli görülmektedir. TRT World'ün web sitesinde 6 Mart 2019 tarihinde yayınlanan “ABD’li General Türkiye'nin S-400 Savunma Sistemini Satın Almayı Tekrar Düşünmesini Umuyor" başlıklı habere göre, ABD tarafından yapılan açıklamalar sonucu Türkiye'nin S-400 Savunma füzesini satın olması durumunda F-35 programından çıkarılacağına dair açıklamalarına yer verilmektedir. ABD'nin açıklamaları sonrası 7 Mart 2019 tarihinde yayınlanan “Türkiye Cumhurbaşkanı Erdoğan: S-400'ün Rusya ile Anlaşması Yapıldı" başlıklı habere göre ise, anlaşmanın tamamlandığının vurgulanması, füzelerin birlikte üretileceğinin ve yeni nesil S-500'lerinde satın alınabileceğine dair açılklamaları dikkat çekmektedir. 7 Mart 2019 tarihinde yayınlanan “Türkiye'nin S-400 Sistemini Satın Alması NATO'nun Pahasına Değil” başlıklı diğer yorum/haberde, NATO müttefiki olarak Türkiye'nin, endișeleri gidermek üzere satın alma sebeplerini aktardığı görülmektedir. Söz konusu haberde, Türkiye'nin S-400 Anlaşması öncesi ABD'den Patriot almak istediğine değinilerek Türkiye'nin acil olarak hava sahasındaki güvenliği korumasının gerekliliği vurgulanmaktadır. ABD’nin açıklamaları sonrasında TRT World aracılığıyla yapılan resmî açıklamalar, anlaşmanın tarafı olan Türkiye'nin bakış açısının dış kamuoylarına duyurulması açısından önemlidir. TRT World'ün web sitesinde anlaşmaya yönelik Türkiye'nin resmî açıklamalarını içeren 33 haberin yayınlandığı görülmektedir. Diğer taraftan TRT World'de, ABD ve diğer NATO ülkelerinin S-400 Anlaşmasına yönelik açıklamalarını içeren 33 haber yayınlanmıştır. Türkiye'ye yönelik eleştiri ve yaptırım içeriklerini kapsayan bu haberlerde, NATO ülkesi olan Türkiye'nin Rusya yapımı savunma füzesi satın alması ve S-400'lerin uyum sorunu ve Türkiye'nin 
F-35 programındaki konumunun askıya alınması konularındaki haberin yoğun olarak yayınlandığı görülmektedir. Örnek olarak, Türkiye tarafından S-400 Anlaşmasının devam ettirileceğine dair yayınlanan haberlerin ardından, 1 Nisan 2019 tarihinde yayınlanan "ABD, S-400 anlaşmasıyla Türkiye'ye F-35 teslimatını askıya aldı - Pentagon" başlıklı habere göre, Pentagon tarafından Türkiye'nin satın almış olduğu F-35'lerin teslimatını durdurduğuna ilişkin açıklaması dikkat çekmektedir.

TRT World'ün web sitesinde S-400 Anlaşmasına dair yayımlanan haberleri genel olarak değerlendirdiğimizde, TRT World'ün kuruluş amaçlarına uygun olarak Türkiye'nin S-400 Anlaşmasına açıklamalarının dış kamuoyları ile paylaşıldığı ve anlaşmaya yönelik Türkiye'nin bakış açısının yansıtıldığı görülmektedir. Özellikle Rusya ve Türkiye'nin hükümet yetkilileri tarafından yapılan açıklamalara yer verildiği görülmektedir. Ayrıca, ABD ve diğer NATO yetkililerinin anlaşmaya yönelik eleştirilerini içeren açıklamaları sonrasında TRT World'de yayınlanan cevap niteliğindeki haberler anlık iletişim ve bilgilendirme ile Türkiye'nin kamu diplomasisi faaliyetleri açısından önemli bir yere sahiptir.

Tablo 5. Konularına Göre TRT World'ün İnternet Haber Sitesinde Yayımlanan Haber Başlığı Örnekleri

\begin{tabular}{|l|l|l|}
\hline Haber Konusu & Haber Başlığı & Yayın Tarihi \\
\hline S-400 Anlaşmasına dair haber & $\begin{array}{l}\text { “Neden Türkiye Rusya'nın S-400 } \\
\text { Savunma Sistemini Satın Alıyor?” }\end{array}$ & 18 Ağustos 2017 \\
\hline Teslimat sürecine dair haberler & $\begin{array}{l}\text { "Türkiye S-400 Füzelerine } \\
\text { Ödeme Yapmaya Başlıyor” }\end{array}$ & 12 Eylül 2017 \\
\hline $\begin{array}{l}\text { NATO ve ABD’ nin anlaşmaya } \\
\text { yönelik açıklamalarına dair haberler }\end{array}$ & $\begin{array}{l}\text { “ABD, S-400 anlaşmasıyla Türkiye’ye } \\
\text { F-35 teslimatını askıya aldı - Pentagon” }\end{array}$ & 1 Nisan 2019 \\
\hline $\begin{array}{l}\text { Türkiye'nin anlaşmaya yönelik } \\
\text { açıklamalarına dair haberler }\end{array}$ & $\begin{array}{l}\text { “Türkiye'nin S-400 Sistemini Satın } \\
\text { Alması NATO'nun Pahasına Değil” }\end{array}$ & 7 Mart 2019 \\
\hline
\end{tabular}

\section{Sonuç ve Değerlendirme}

Devletler iknaya ve uzun süreli ilişkilerin inşasına dayalı yumuşak güç unsurlarına yatırım yapmayı önemserken Joseph Nye tarafından kavramsallaştırılan yumuşak gücün en kilit uygulama aracı kamu diplomasisi de belli bir anlamda yumuşak güce ulaşabilmenin yöntemi olarak ön plana çıkmaktadır. Bu noktada devletler ve devlet dışı aktörlerin bilgi alışverişinde bulunmak ve dış kamuoylarına iletilmesi amaçlanan haberlerin anlık olarak iletilmesini sağlamak için uluslararası yayın kuruluşlarına başvurduğu görülmektedir. Kamu diplomasinin bir unsuru olarak uluslararası yayıncılık faaliyetleri, modern kitle iletişim araçlarının kullanılarak yabancı toplumları etki altına alınması için önemli bir araçtır. Uluslararası yayıncılık aracılığıyla devletler yabancı hedef kitlelere yönelik açıklamalar, bilgilendirmeler hazırlayarak gündemde yer almayı hedeflemektedir. Uluslararası yayınlar aracılığıyla günlük iletişim ve bilgilendirme ile dış politikayı destekleyen açıklamalar yapılabilirken aynı zamanda yabancı hedef kitlelerden gelen eleştirilere ve ortaya çıkan krizlere eş zamanlı yanıtlar da verilebilmektedir.

Uluslararası yayıncılık kuruluşları aracılığıyla kamu diplomasisi faaliyetlerinin incelendiği bu çalıșmada, Türkiye ve Rusya arasında imzalanan S-400 Anlaşmasına ilișkin TRT WORLD, VOA, RT'nin internet haber sitelerinde yer alan haber içerikleri 2017 yllı Eylül ve 2019 yılı Ekim ayını kapsayan süre örneklem alınarak Joseph Nye'ın kamu diplomasisini boyutları sınıflandırılması üzerinden analiz edilmiștir. Buna göre, anlaşma ve S-400'lerin teslimat sürecine, NATO ve ABD'nin anlaşmaya yönelik açılklamalarına ve Türkiye'nin 
açıklamalarına dair belli konu başlıklarının ön plana çıktığı tespit edilmiştir. VOA, RT ve TRT World'ün internet haber sitelerinde ABD bașta olmak üzere diğer NATO ülkelerinin anlaşmaya yönelik eleștirilerini ve yaptırım tehditlerini içeren 119 haber yayınlanırken, Türkiye'nin açıklamaların içeren 85 haber içeriği yayınlandığı görülmektedir. $\mathrm{Bu}$ noktada TRT World yayıncılığı aracılığıyla, S-400 Anlaşmasının gerekçelerine yönelik bilgilendirmeler, NATO ve ABD’nin eleştirilerine anlık olarak verilen yanıtlar, Türkiye'nin açıklamalarının doğrudan paylaşılması bakımından önemlidir. Bununla birlikte, S-400 anlaşmasına taraf olan Türkiye'nin bakış açısının uluslararası alanda yansıtılması, mevcut ön yargıların ve endişelerin ortadan kaldırılması ve yabancı kamuoylarının ikna edilmesi için TRT World'ün varlığının zorunlu olduğu görülmektedir. Diğer yandan uluslararası yayıncılık aracılığıyla kamu diplomasisi faaliyetlerinin başarısını mevcut uluslararası ilişkiler gündemi dışında değerlendirmek mümkün görünmemektedir. $\mathrm{Bu}$ noktada gündemin sürekli olarak değiştiği uluslararası ilişkiler ortamında günlük bilgilendirme ile birlikte kamu diplomasinin diğer boyutlarının da süreci dahil edilmesi gerekmektedir. Bu noktada Türkiye'nin, anlaşmaya taraf olan Rusya'ya ve NATO'nun önemli bir aktörü olan ABD'ye yönelik stratejik iletişim faaliyetleri ile Türkiye'nin dış politikasının doğru olarak algılanması ve sürdürülebilir ilişkiler kurmak adına diyalog ortamının inşası edilmesi bakımından önemlidir.

Sonuç olarak, devletlerin kendi bakış açılarını yabancı kamuoylarına duyurmak adına uluslararası yayın kuruluşları aracılığıyla günlük iletişim ve bilgilendirme faaliyetlerinin anlık iletişim ortamında zorunlu olduğu görülmektedir. Bununla birlikte uluslararası yayıncılık yapan kuruluşlar aracılığıyla yabancı toplumların etki altına alınabilmesi için kamu diplomasisinin diğer boyutlarıyla birlikte uzun vadeli, kalıcı ve diyaloğa dayalı ilişkiler inşa etmesi gerektiği sonucuna varılmıștır.

\section{Kaynakça}

Ammon, R. J. (2001). Global television and the shaping of world politics : CNN, telediplomacy, and foreign policy. In McFarland.

Aydemir, E. (2016). Dış Politikada Yumuşak Güç ve Medya. İstanbul: Kalkedon Yayıncılık.

Baritci, F., \& Aydeniz, H. (2019). Kamu Diplomasisi Aracı Olarak Medya: Trt World Örneği. Erciyes İletişim Dergisi, 6(2), 1551-1576. https://doi.org/10.17680/ erciyesiletisim.509054

Bostancı, M. (2012). Kamu Diplomasisinde Medyanın Rolü ve Önemi. İstanbul: Anahtar Kitaplar Yayınevi.

Cull, N. J. (2006). "Public Diplomacy” Before Gullion: The Evolution of a Phrase | USC Center on Public Diplomacy. https://uscpublicdiplomacy.org/blog/publicdiplomacy-gullion-evolution-phrase. Erişim Tarihi: 12.03. 2021

Cull, N. J. (2008). Public Diplomacy: Taxonomies and Histories. The ANNALS of the American Academy of Political and Social Science, 616(1), 31-54. https://doi. org/10.1177/0002716207311952

Devran, Y. (2016). Yeni Türkiye'nin Küresel Sesi TRT World: Fırsatlar ve Güçlükler TRT World Television, Global Voice of New Turkey: Opportunities and Challenges. Intermedia International E-Journal, 2(2). Retrieved from https:// dergipark.org.tr/tr/pub/intermedia/568465

Erzen, M. Ü. (2012). Kamu Diplomasisi. İstanbul: Derin Yayınları. 
Keşvelioğlu, A., Alpaslan, O., Edebali, M. A., \& Türkcan, M. L. (2019). Turkey’s Procurement of the S-400 System: An Explainer. In TRT WORLD RESEARCH CENTRE. https://researchcentre.trtworld.com/images/files/info-packs/TurkeyS400-infopack.pdf

Kibaroğlu, M. (2019). On Turkey's Missile Defense Strategy: The Four Faces of the S-400 Deal between Turkey and Russia. In PERCEPTIONS: Journal of International Affairs (Vol. 24). http://sam.gov.tr/wp-content/uploads/2019/04/SAM-Papers-

Nye, J. S. (2005a). Soft Power: The Means To Success In World Politics. PublicAffairs.

Nye, J. S. (2005b). Yumuşak Güç. Ankara: Elips Yaynıvi.

Nye, J. S. (2008). Public Diplomacy and Soft Power. The ANNALS of the American Academy of Political and Social Science, 616(1), 94-109. https://doi. org/10.1177/0002716207311699

Özkan, A. (2012). TASAM | Kamu Diplomasisi ve Medya. Retrieved March 12, 2021, from https://tasam.org/tr-TR/Icerik/4881/kamu_diplomasisi_ve_medya

Öztas, T. (2019). Turkey's purchase of S-400 system is not at the expense of NATO. TRT WORLD.

Pamment, J. (2012). New public diplomacy in the 21st century: A comparative study of policy and practice. In New Public Diplomacy in the 21st Century: A Comparative Study of Policy and Practice. Taylor and Francis. https://doi. org/10.4324/9780203096734

Potter, E. H. (2002). Information Technology and Canada's Public Diplomacy. In E. H. POTTER (Ed.), Cyber-Diplomacy (pp. 177-200). McGill-Queen's University Press. Retrieved from http://www.jstor.org/stable/j.ctt7zt0w.12

Russian Today. (2021). About RT. https://www.rt.com/about-us/ Erişim Tarihi: 11.03. 2021.

Sancar, G. A. (2015). Kamu Diplomasisinde "İlişki İnşa Etme" Söylemi.

Snow, N., \& Taylor, P. M. (2008). Routledge Handbook of Public Diplomacy. In N. Snow, N. Snow, \& P. M. Taylor (Eds.), Routledge Handbook of Public Diplomacy. Routledge. https://doi.org/10.4324/9780203891520

Szondi, G. (2008). Public Diplomacy and Nation Branding: Conceptual Similarities and Differences.

TRT World. (2021.). Our Story. Retrieved March 11, 2021, from https://www.trtworld. com/about

Tuch, H. N. (1990). Communicating with the World. In Communicating with the World. Palgrave Macmillan US. https://doi.org/10.1007/978-1-349-60512-5

Turkey starts paying for Russian S-400 missiles. (2017). TRT WORLD. https://www. trtworld.com/turkey/turkey-starts-paying-for-russian-s-400-missiles-10426

TRT World. (2019). US general hopes Turkey reconsiders purchase of S-400 defence system. https://www.trtworld.com/americas/us-general-hopes-turkeyreconsiders-purchase-of-s-400-defence-system-24691 
TRT World (2019). US suspends F-35 deliveries to Turkey over S-400 deal - Pentagon. https://www.trtworld.com/turkey/us-suspends-f-35-deliveries-to-turkey-over-s400-deal-pentagon-25465

Voice of America. (2021). Mission and Values. https://www.insidevoa.com/p/5831.html Yağmurlu, A. (2007). "Halkla İlişskiler Yöntemi Olarak Kamu Diplomasisi” İletişim Araştırmaları Dergisi, 5(1): 9-38. Retrieved from https://www.academia. edu/4795612/Yağmurlu_Asl__2007_Halkla_illişkiler_Yöntemi_Olarak_Kamu_ Diplomasisi_İletişim_Araştırmaları_Dergisi_5_1_9_38 


\title{
Examining the S-400 Missile Deal in the Context of the Public Diplomacy Through International Broadcasting Organizations: The Cases of VOA, RT, and TRT World
}

\author{
Şeyma Filiz (Res. Asst.)
}

\section{Extended Abstract}

Public diplomacy is considered as a communication effort of countries to develop mutual understanding and relations with foreign target audiences about their own values, ideas and ideals. Using soft power tools instead of using hard power in international relations is a more persuasive way to influence foreign public opinion. New communication technologies, which provide opportunities for dialogue-based relations have been playing a critical role in public diplomacy activities. From this point of view, international broadcasting is seen as one of the main dimensions of public diplomacy in order to reach a wide range of audiences.

International broadcasting is one of the essential ways of creating mutual understanding and influencing the public opinion among countries in terms of political, economic and cultural differences. As a part of the public diplomacy activities provides an environment for states to introduce themselves to the foreign public and express their policies correctly. At this point, international broadcasting is seen as a tool of the public diplomacy activities to get public support for policies.

Public diplomacy, as a key tool of soft power in the context of the international broadcasting, is expressed as some attempts of countries to influence the citizens of other countries following their own private purposes. In addition, public diplomacy activities can be designed for various objectives and dimensions. From this point of view, with daily communication and information, especially through international broadcasting organizations, states prepare statements and information for external target audiences. Daily communication and information through international broadcasting is not only important for making statements in support of foreign policy but also for simultaneous response to criticism and crises from foreign countries.

The aim of this study is to examine the digital media contents of international news organizations financed by the states in the context of the public diplomacy. In this framework, the media contents published on the websites of TRT World, Russia Today, and Voice of America regarding the S-400 Air Defense System deal between Russia and Turkey are analyzed by using the content analysis method. Also, this study focuses on the period between September 2017 and October 2019, which covers the period when the S-400 Deal was first brought to the international agenda and the agreement was completed and delivered.

The news about the S-400 Deal published on Voice of America, Russian Today, and TRT World websites were classified and analyzed. In these selected periods, covering September 2017 and October 2019, it was determined that 306 news related to the agreement were published on the websites of VOA, RT, and TRT World. According to the findings, while 71 of the published news are about the details of the deal, 31 of them are about the features of the S-400s and the delivery process. While it was determined 
that 119 news items were published regarding the criticisms of the USA and other NATO countries against the agreement, especially the USA's threats of sanctions against Turkey and the suspension of Turkey's role in the F-35 program, it was observed that there were 85 news items in which Turkey's statements were published. In particular, Turkey's instant response to criticism of the S-400 Deal through TRT World is vital role in terms of eliminating concerns and building international goodwill relations. From this point of view, in addition to "daily communication and informing", which is the first dimension of public diplomacy, other dimensions such as "strategic planning and country branding" and "establishment and institutionalization of long-term relations" should be included in the process. However, it should be emphasized that it is not possible to evaluate the success of public diplomacy activities without the current international agenda. Based on the S-400 agreement, the existence of TRT World plays a vital role in reflecting Turkey's perspective to the international arena and providing information flow to the public.

On the other hand, it does not seem possible to evaluate the success of public diplomacy activities through international broadcasting without the current international agenda. At this point, it is necessary to include the process of other dimensions of public diplomacy along with the daily informing approach in the international relations environment where the agenda is continuously changing. This is because Turkey's strategic communication activities towards Russia and the USA are important in terms of building a favorable dialogue.

As a result, with new communication processes, it is seen that daily communication and information activities are needed in order to announce the perspectives of states to foreign public opinion through international broadcasting organizations. However, it was concluded that long-term, permanent and dialog-based relations with other dimensions of public diplomacy should be established in order to influence the minds and hearts of foreign publics through public diplomacy activities.

Keywords: Communication, Public Diplomacy, S-400 Agreement, International Broadcasting, TRT World, Voice of America, Russian Today.

Bu makale intihal tespit yazılımlarıyla taranmıştır. Intihal tespit edilmemiştir.

This article has been scanned by plagiarism detection softwares. No plagiarism detected.

Bu çalışmada "Yükseköğretim Kurumları Bilimsel Araştırma ve Yayın Etiği Yönergesi” kapsamında uyulması belirtilen kurallara uyulmuştur.

In this study, the rules stated in the "Higher Education Institutions Scientific Research and Publication Ethics Directive" were followed.

Araştırma tek bir yazar tarafından yürütülmüştür.

The research was conducted by a single author.

Çalışma kapsamında herhangi bir kurum veya kişi ile çıkar çatışması bulunmamaktadır.

There is no conflict of interest with any institution or person within the scope of the study. 